\title{
Abdel-Fattah HMM
}

\section{Emotional Intelligence and Emotional Stability in Crises}

Neuropsychiatry Specialist, Abbassia Psychiatric Hospital, Cairo, Egypt.

Corresponding Author: Abdel-Fattah HMM, Neuropsychiatry Specialist, Abbassia Psychiatric Hospital, Cairo, Egypt. Received date: April 23, 2020; Accepted date: June 27, 2020; Published date: July 15, 2020.

Citation: Madadi R. mohamadi A, (2020) Iodide mumps Occurs for the Second Time After Coronary Angiography:case report. (2020) EhlersDanlos and respiratory function. Clinical data on a cohort of 5,700 patients: oxygen therapy and physical rehabilitation medicine (P.R.M.). J Neuroscience and Neurological Surgery. 6(4); DOI:10.31579/2578-8868/127

Copyright: (92020 Asghar Mohamadi, This is an open-access article distributed under the terms of the Creative Commons Attribution License, which permits unrestricted use, distribution, and reproduction in any medium, provided the original author and source are credited.

Abstract
The current study is aimed at putting the light on the role of emotional intelligence and emotional stability on
confronting crises in general and the existing crisis of COVID-19 which has global impact till the present moment.
Data were collected from different sources particularly the recent international scientific issues and publications as
Centers of Disease Control and Prevention (CDC) as well as the current national issues. Data revealed that there is
lack of awareness regarding the existing pandemic of corona virus (COVID-19) which requires clearance of the
correlation between the physical and psychological impact on the human being all over the world. Also to clarify the
importance of the emotional intelligence and emotional stability in confronting the existing fear and anxiety caused
by corona virus.
Finally there are certain recommendations could be taken in consideration to relieve panic and anxiety among the
people facing the stress of mixed symptoms and signs of corona virus and how to deal with this crisis.

\section{Abbreviations}

1. $\quad \mathrm{CDC}=$ Centers of Disease Control and Prevention

2. $\mathrm{EI}=$ Emotional Intelligence

3. $\mathrm{ES}=$ Emotional Stability

4. COVID-19 = Corona Virus Disease 2019

\section{Introduction}

In light of the sudden and global spread of a catastrophe like the Corona virus (COVID-19) which affected millions of lives worldwide, not only physically but also emotionally in the form of panic attacks, obsessional behavior, anxiety, and fear. Malbehavior has been appeared such as selfishness and storing goods which affected social cohesion and national income.

Through our duty in the field of psychiatry towards humanity, we bear a great responsibility on us to confront such crises, in which we wish to help the largest number of people at the world level. At this time, inaccurate information is a serious danger, whether in the psychological aspect or the organic side, and a lot of people around the world have their medical information through social media and not the approved medical sites. Therefore, it is necessary to differentiate between health information and rumors as well. Also it is important to clarify the concept and acquisition of emotional intelligence and emotional stability in the face of crises.

\section{Discussion}

What is Emotional Intelligence?
Drawing from several different sources, a simple definition of emotional intelligence (EI) describes an ability to monitor your own emotions as well as the emotions of others, to distinguish between and label different emotions correctly, and to use emotional information to guide your thinking and behavior and influence that of others (Salovey and Mayer, 1990 and Goleman, 1995).

Emotional intelligence is what we use when we empathize with our coworkers, have deep conversations about our relationships with significant others, and attempt to manage an unruly or distraught child. It allows us to connect with others, understand ourselves better, and live a more authentic, healthy, and happy life.

\section{The five Elements of the EI Model:}

According to Goleman (1995), there are five components or elements of emotional intelligence:
1. Self-Awareness
2. Self-Regulation
3. Motivation
4. Empathy
5. Social Skills

Self-awareness can be defined as the ability to recognize and understand your own emotions. It is the foundational building block of emotional intelligence since regulating ourselves, having empathy for others; and so on all rely on identifying and understanding emotion in us. 
Self-regulation is one step further - to have high EI, we must not only be able to recognize our own emotions, but we must also be able to appropriately express, regulate, and manage them.

People who have high EI also generally possess more intrinsic motivation. In other words, people high in EI are motivated for internal reasons rather than external rewards like gaining wealth, respect, or fame. Those with high EIs are motivated for their own personal reasons and work toward their own goals.

Empathy can be defined as the ability to understand how other people are feeling and recognize, on an intimate level, how you would feel if you were in their position. It does not mean you sympathize with, validate, or accept their behavior just that you can see things from their perspective and feel what they feel.

Finally, social skills are what allow people to interact socially with one another and to successfully navigate social situations. Those with high EI generally have higher-than-average social skills and are able to effectively pursue their goals and get the outcomes they want when interacting with others (Salovey and Mayer, 1990).

\section{Emotional Intelligence Affects Decision-Making:}

Related to the previous point, high emotional intelligence will also improve decision-making abilities. Those who have a good understanding of themselves and those around them are more likely to weigh all the options, keep an open mind, and remove all irrelevant emotions from the decision-making process.

\section{Emotional Intelligence and Communication:}

To expand a bit on the previous section, emotional intelligence is closely related to communication skills; people with high EIs tend to be proficient in their communication abilities.

\section{Building Resilience with Emotional Intelligence:}

Finally, another important reason to pay attention to emotional intelligence is how it affects one's resilience. People who are high in EI are also generally able to pick themselves up when they fall.

In fact, emotional intelligence is considered by some to be a direct source of resilience. It was found that emotional intelligence is directly related to resilience and, through that connection, it's related to achievement and achievement motivation.

\section{Concept of Emotional Stability (ES):}

Emotional stability is the capacity to maintain ones emotional balance under stressful circumstances. It is the opposite of emotional instability and neuroticism.

Emotionally stable persons tolerate minor stresses and strains of day to day living without becoming emotionally upset, anxious, nervous, tense, or angry. They are able to maintain composure under minor emotional stress. They are fairly constant in their basic mood, and they generally revert quickly to that state following those occasions when they have experienced considerable stress or have been exceptionally provoked. The unstable person, on the other hand, is subject to fairly wide, frequent, and often unpredictable mood shifts that may swing from pole to pole.

Emotional stability enables the person to develop an integrated and balanced way of perceiving the problems of life. This organizational ability and structured perception helps one to develop reality-oriented thinking, judgment and evaluation ability. One develops feelings, perceptions and attitudes that help in understanding the realities of life and conditions and circumstances that create miserable situations in life. Such understanding helps one promote high ego strength.

This balance is playing a role in several natures and emotions, like pessimism/optimism, anxiety/calmness, aggression/tolerance, dependence/autonomy, emotion/logic, apathy/empathy.

\section{$\underline{\text { Are Emotionally Intelligent People More Emotionally Stable? }}$}

The answer was yes as Mood variability and instability were found to be very closely related to each other, measuring essentially the same construct. Inertia is relatively independent. It's was not related to mean mood scores which contradicts the results of other studies and can be explained by the use of the experience sampling procedure. It's was positively related to the inertia of a positive mood with high arousal and a negative mood with low arousal. In addition, a negative relationship between EI and the instability of tension was found. Most of the correlations were low. Further studies with higher statistical power are needed for more decisive conclusions (Emmerling $\boldsymbol{e t}$ al, 2008).

\section{Emotional Intelligence and Stability in the Face of COVID-19:}

COVID-19 is an infectious condition, which means it can be spread, directly or indirectly, from one person to another. It is caused by the newly discovered coronavirus, called as novel coronavirus, first identified in Wuhan, China, in December 2019. The lack of verified facts and floating rumors are to be blamed for the so much panic.

People are not only physically vulnerable to crises, but psychologically vulnerable too. Every major incident will have mental health consequences for some of those involved. It has been estimated that up to $80 \%$ of those affected by a crises will have short-term mild distress, $20-40 \%$ a psychological disorder in the medium term, and up to $5 \%$ may be left with a long-term problem. Fortunately, the majority of those affected will recover without professional intervention (Greaves and Hunt, 2017).

No one knows what lasting effect the coronavirus will have on the economy, whether it will subside or keep spreading and force more areas. This disruption is testing everyone's emotional and intelligence and emotional stability. Those who survive are not the strongest or the most intelligent, but the most adaptable to change.

It's the responsibility of leaders to show empathy, unprecedented optimism, and flexibility that will lead the people out of this crisis. It may all come down their ability to self-direct and problem-solve on a regular basis. 
The outbreak of COVID-19 may be stressful for people. Fear and anxiety about a disease can be overwhelming and cause strong emotions in adults and children. Coping with stress will make the people and the community stronger. People who may respond more strongly to the stress of the crisis include:

1. Older people and people with chronic diseases who are at higher risk for COVID-19.

2. Children and teens.

3. People who are helping with the response to COVID-19, like doctors and other health care providers, or first responders.

4. People who have mental health conditions including problems with substance use.

Stress during an infectious disease outbreak like COVID-19 can include:

1. Fear and worry about one's health and the health of his loved people.

2. Changes in sleep or eating patterns.

3. Difficulty sleeping or concentrating.

4. Worsening of chronic health problems.

5. Increased use of alcohol, tobacco, or other drugs.

People with preexisting mental health conditions should continue with their treatment and be aware of new or worsening symptoms. Taking care of oneself, his friends, and family can help him cope with stress. Helping others cope with their stress can also make the community stronger (CDC 2020).

While this crisis might blow over, it probably won't happen in the next few weeks, it is required to develop the emotional intelligence skills. How to create a level of respect and calm for self and others:

1. Be empathetic; keep in mind that this event is impacting everyone, not just certain people. Nobody has an idea what other people are going through will make leaders more generous and calmer.

2. Be innovative; technology has made it possible to work anywhere. With video conferencing, email, and online chat, the work could be continued even from home. All the solutions are at the fingertips, people just have to embrace the change.

3. Be confident; a time of crisis requires a leader who is confident in their ability to make a decision and to see it through. They must offer the best chance of overcoming a crisis. They need to make sure their subordinates are emotionally intelligent enough to deal with that crisis whenever it comes.

4. Be flexible; if there is an event planned for the next few months, it is considered to take a wait-and-see approach rather than canceling it now, or consider flipping the concept and content to a truly digital event by webcasting all the relevant speakers, panels, and networking events. Also to develop and circulate policies now so that staff knows whether to come to work and when to stay home. Instead of inviting vendors or guests to the event, it is better to share the latest protocols with them via email to avoid the spread of the virus through fingers touching check-in reception devices, pens, and countertops at the registration desk.

5. Be optimistic; governmental organizations, medical institutions, the media, and business leaders around the world are seeking solutions and communicating with the public to prevent panic and spread of disinformation. This is the time to be grateful that all the needed information could be accessed to make educated decisions. Leaders must show their optimism, empathy and gratitude for the work people have done and to be thankful for their understanding. This sense of optimism and gratitude will allow solutions and new ideas to come through.

Being able to see the light at the end of the tunnel during a crisis is a key skill that leaders must have to navigate those times. Resilience in the face of a crisis, particularly if others around them are faltering, is one of the most important attributes.

By taking responsibility of the mindset, to be optimistic and find solutions, leaders are helping themselves and others. This is a human and emotionally intelligent thing to do.

\section{How to reduce stress in crises:}

Sharing the facts about COVID-19 and understanding the actual risk to oneself and people he cares about can make an outbreak less stressful. On sharing accurate information about COVID-19 it can help making people feel less stressed and allow connection with them.

Children and teens react, in part, on what they see from the adults around them. When parents and caregivers deal with the COVID-19 calmly and confidently, they can provide the best support for their children. Parents can be more reassuring to others around them, especially children, if they are better prepared. There are many things could be done to support child:

1. Giving enough time to talk with the child or teen about the COVID-19 outbreak. Answering questions and sharing facts about COVID-19 in a way they can understand.

2. Reassuring child or teen that they are safe. Letting them know it is ok if they feel upset. Sharing with them how adults deal with their own stress so that they can learn how to cope.

3. Limiting family's exposure to news coverage of the event, including social media. Children may misinterpret what they hear and can be frightened about something they do not understand.

4. Keeping up with regular routines. If schools are closed, it is necessary to create a schedule for learning activities and relaxing or fun activities. 
5. Parents must be role models; they take breaks, get plenty of sleep, exercise, and eat well, and connect with their friends and family members.

\section{Recommendations}

There are certain ways to ease the Coronavirus anxiety:

1. Searching and learning: Do as much research as you can about you can about the risks. Having procedural knowledge has been shown to be a strong protective factor.

2. Identifying the source of anxiety: if we can identify our anxiety-driven reactivity, we can get some distance from it, rather than being propelled into action before we have calmed down enough to do our best thinking.

3. Accepting the worries: Having an emotional reaction as anxiety, fear, anger or frustration is absolutely normal and is a sign that our body's natural protective mechanisms have been triggered.

4. Considering the received information: Try and challenge the information you receive by questioning how rational and free from bias it is. You may find it useful to restrict your input to sources of information or consciously seek out information only from trusted outlets and bodies.

5. Taking self-care: we can learn ways to calm ourselves down and find a little peace of mind. Action is powerful, even if we start with just one thing.

6. Practicing self-compassion: don't be hard on yourself when you can't shut yourself off from fear and pain. Fear isn't fun, but it signals that we are fully human.

7. Thinking about the impact on others: Take a moment to consider how others are feeling about the coronavirus threat at the moment. This might be those who are currently suffering, or those that are quarantined and waiting to find out if they have the virus.

8. Asking for help: so avoid being a do-it-yourselfer when you're not qualified. Grab some other clear-thinking person to ask what he thinks or what he would do.

9. Connecting and connecting: social distancing and mandates to shelter in place may require us to stay in our homes, but that doesn't mean we have to isolate. It's essential to stay in communication with family, friends, neighbors and other resources.

10. Avoiding shaming and blaming: anxiety can be useful when it signals a problem and motivates us to unite to solve it. If we make a deliberate effort to hold on to our humanity, it can bring us together.

11. Focusing on what could be controlled: You may see that you are taking lots of your time and energy worrying about things you can't control rather than taking actions you can. Create a list of two columns; in the first column write everything that you can control and focus your efforts and thoughts on what you can do to control the threat and protect yourself.

12. Thinking about prevention not avoidance: People who, when under threat, are able to consider how others are thinking and feeling, and are more likely to engage in productive health behaviors (preventive behavior) that contribute much better to wellbeing of yourself and others than avoiding people and places.

13. Focusing on the present moment: It is important to try and take a step back and focus on what is happening right here and right now.

14. Preparing for the worst: we trust our capacity to make necessary changes, recognize where we have agency and take common sense, precautionary measures now.

15. Preventing anxiety to be pandemic too: we should not let fear lead us into isolation or stop us from acting with clarity, compassion and courage.

Finely Emotional Intelligence and Emotional Stability skills are the main core in dealing with human crises.

\section{References}

1. Centers of Disease Control and Prevention (CDC) (2020): Manage anxiety and stress. In: Corona Virus Disease 2019 (COVID-2019), how to prepare.

2. Emmerling, R.J.; Shanwal, V.K. and Mandal, M.K. (2008): Emotional intelligence: Theoretical and Cultural Perspectives, Nova Publishers, 233 pp.

3. Goleman, D. (1995): Emotional intelligence. Bantam Books, Inc., 262 pp.

4. Greaves, I. and Hunt, P. (2017): Psychological aspects of major incidents. In: Oxford Manual of Major Incident Management. Oxford University Press; Print ISBN-13: 9780199238088 .

5. Mayer, J.D.; Salovey, P. and Caruso, D. (1997): Models of emotional intelligence. In: Handbook of intelligence by Sternberg, R.J. Cambridge University Press, 397 pp.

6. Salovey, P. and Mayer, J.D. (1990): Emotional intelligence. Imagin. Cogn. Pers.: 9 (3): 185-211. 
(c) (1)

This work is licensed under Creative Commons Attribution 4.0 License

To Submit Your Article Click Here: Submit Manuscript

DOI:10.31579/ 2578-8868/127
Ready to submit your research? Choose Auctores and benefit from:

* fast, convenient online submission

* rigorous peer review by experienced research in your field

* rapid publication on acceptance

* authors retain copyrights

* unique DOI for all articles

* immediate, unrestricted online access

At Auctores, research is always in progress.

Learn more www.auctoresonline.org/journals/neuroscience-andneurological-surgery 